\title{
FAKTOR DEMOGRAFI DOMINAN YANG MEMPENGARUHI PROYEK KONSTRUKSI JALAN DI PEDESAAN INDONESIA
}

\author{
Samuel Semaya ${ }^{1}$ dan Basuki Anondho \\ ${ }^{1}$ Program Studi Sarjana Teknik Sipil, Universitas Tarumangara, Jl.Letjen S. Parman No.1 Jakarta \\ Email: samuelsemaya@gmail.com \\ ${ }^{2}$ Program Studi Sarjana Teknik Sipil, Universitas Tarumangara, Jl.Letjen S. Parman No.1 Jakarta \\ Email: basukia@ft.untar.ac.id
}

Masuk: 15-01-2020, revisi: 08-02-2020, diterima untuk diterbitkan:19-02-2020

\begin{abstract}
National development for almost 70 years since independence Indonesia has produced various advances, but it was realized that the development process carried out so far turned out to have caused a residual problem of development inequality, especially in rural areas. the development approach which only emphasizes macroeconomic growth tends to lead to a large development gap between regions. Therefore, this study would like to conduct a study of the dominant demographic characteristic factors affecting construction projects in rural Indonesia. The research was conducted by distributing questionnaires to contractors selected by the Ministry of Village. The source of the questionnaire used is through previously identified journals and books. The method used in analyzing data is factor analysis. Data analysis was carried out starting from the validity test, reliability test, KMO test, MSA test, communality test, and determining the dominant influence factor. Based on the data analysis conducted, it was concluded that the most dominant demographic characteristic factors affecting road construction projects in rural Indonesia were education, gender, age, urbanization, and labor.
\end{abstract}

Keywords: demography, rural, factor.

\begin{abstract}
ABSTRAK
Pembangunan nasional selama hampir 70 tahun sejak Indonesia merdeka telah menghasilkan berbagai kemajuan, namun disadari bahwa proses pembangunan yang dilaksanakan selama ini ternyata telah menimbulkan residu masalah kesenjangan pembangunan, khususnya wilayah pedesaan. pendekatan pembangunan yang hanya menekankan pada pertumbuhan ekonomi makro, cenderung menimbulkan terjadinya kesenjangan pembangunan antar wilayah yang cukup besar. Oleh karena itu, studi ini ingin melakukan penelitian tentang faktor demografi dominan yang mempengaruhi proyek konstruksi jalan di pedesaan Indonesia. penelitian dilakukan dengan penyebaran kuesioner kepada kontraktor yang dipilih oleh Kementerian Desa. Sumber kuesioner yang digunakan adalah melalui jurnal dan buku yang telah diidentifikasi lebih dulu. Metode yang dipakai dalam menganalisis data adalah analisis faktor. Analisis data dilakukan mulai dari uji validitas, uji reliabilitas, uji KMO, uji MSA, uji komunalitas, dan menentukan faktor pengaruh dominan. Berdasarkan analisis data yang dilakukan, diperoleh kesimpulan bahwa faktor demografi yang paling dominan yang mempengaruhi terhadap proyek konstruksi jalan di pedesaan Indonesia adalah pendidikan, jenis kelamin, usia, urbanisasi, dan tenaga kerja.
\end{abstract}

Kata kunci: demografi, pedesaan, faktor.

\section{PENDAHULUAN}

Pembangunan nasional selama hampir 70 tahun sejak Indonesia merdeka telah menghasilkan berbagai kemajuan, namun disadari bahwa proses pembangunan yang dilaksanakan selama ini ternyata telah menimbulkan residu masalah kesenjangan pembangunan, khususnya wilayah pedesaan. Menurut Rencana Strategis (Renstra) Direktorat Jenderal Pengembangan Daerah Tertentu tahun 2015, ketimpangan pembangunan antarwilayah telah menghasilkan suatu konsekuensi berupa pemusatan hasil pembangunan pada sebagian wilayah yang dapat berimplikasi pada terbentuknya daerah yang relatif tertinggal jika dibandingkan dengan daerah lain. Pada sisi lain, dari wilayah maju muncul pula apa yang disebut sebagai wilayah tertinggal. RPJMN 2015-2019 menyatakan terdapat 122 kabupaten tertinggal, di mana persebaran daerah tertinggal terkonsentrasi di KTI (dari 122 kabupaten tertinggal, 103 kabupaten tertinggal atau $84.42 \%$ terdapat di KTI). 
Penelitian yang dilakukan oleh Day dan Ellis (2014) menyebutkan bahwa pendidikan, tingkat penghasilan, urbanisasi, dan usia menjadi faktor demografi yang penting yang mempengaruhi proyek konstruksi pedesaan. Ramli, dkk. (2018) menyebutkan bahwa ada beberapa faktor yang mempengaruhi cepat atau lambatnya pembangunan proyek, yaitu tenaga kerja, lokasi, dan pengalaman. Sedangkan penelitian yang dilakukan oleh Tran, dkk. (2015) menyebutkan bahwa hambatan utama untuk proyek pedesaan adalah masalah dokumentasi, kepegawaian, masalah lokasi terpencil, masalah kontraktor kecil, masalah komunikasi, dan lingkungan. Menurut Bogue (1969), ada beberapa faktor yang mempengaruhi pelaksanaan proyek konstruksi di desa tertentu berdasarkan karakteristik demografi.

Di lain sisi, program PDTu, memiliki banyak sekali pembangunan proyek konstruksi di desa tertentu yang harus dibangun. Sehingga, pengetahuan tentang faktor dominan yang mempengaruhi proses pelaksanaan konstruksi jalan dapat membantu manajemen proyek untuk mencapai tujuan pelaksanaan proyek.

\section{METODE PENELITIAN}

\section{Studi Textbook}

1. Rencana Strategis Pengembangan Daerah Tertentu 2015-2019 (RENSTRA 2015-2019)

\section{Studi Jurnal}

1. Urbanisasi dan Pembangunan Pedesaan di Kawasan Metropolitan Beijing-Tianjin-Hebei: Model Gelar Kopling

2. Urbanisasi untuk Semua Orang: Manfaat Urbanisasi di Wilayah Pedesaan Indonesia

3. Dampak Berbeda Karakteristik Sosio-Demografis pada Pilihan Mode Perjalanan Penduduk Kota dan Pedesaan di Cina Timur

4. Penelitian tentang Hubungan antara Kesadaran Keselamatan Lalu Lintas Pengemudi dan Kejadian Kecelakaan Lalu Lintas di Daerah Pedesaan Cina

5. Demografi Penduduk Pedesaan yang Menua

6. Tantangan Manajemen Konstruksi dan Praktik Terbaik untuk Proyek Transit Pedesaan

7. Studi Faktor-Faktor yang Mempengaruhi Keterlambatan Konstruksi di Wilayah Pedesaan di Malaysia

8. Analisis dan Solusi yang Disarankan untuk Jalan Pedesaan di Cina

9. Meningkatkan Penjangkauan Pendidikan Teknik di Daerah Pedesaan melalui Analisis Risiko Teknik

10. Susunan Bentuk pada Bantuan Model Pensiun Pedesaan

Dilakukan identifikasi awal faktor aspek legal dominan berdsasarkan studi melalui textbook dan jurnal yang disebutukan diatas, sehingga menghasilkan 8 (delapan) variabel yang merupakan faktor demografi yang berpengaruh terhadap pembagunan pedesaan.

Tabel 1. Tabulasi Variabel

\begin{tabular}{|c|c|c|c|c|c|c|c|c|}
\hline \multirow[b]{2}{*}{ SUMBER } & \multicolumn{8}{|c|}{ VARIABEL } \\
\hline & 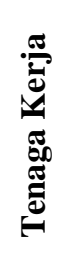 & 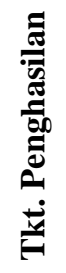 & 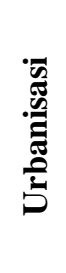 & 产 & 吾 & 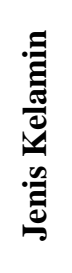 & 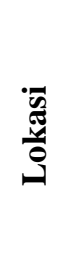 & 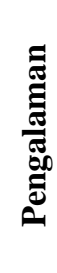 \\
\hline Jurnal 1 & $\sqrt{ }$ & $\sqrt{ }$ & $\sqrt{ }$ & & $\sqrt{ }$ & & & \\
\hline Jurnal 2 & & $\sqrt{ }$ & $\sqrt{ }$ & $\sqrt{ }$ & $\sqrt{ }$ & & & \\
\hline Jurnal 3 & $\sqrt{ }$ & $\sqrt{ }$ & & $\sqrt{ }$ & & $\sqrt{ }$ & $\sqrt{ }$ & \\
\hline Jurnal 4 & & & & & & $\sqrt{ }$ & & $\sqrt{ }$ \\
\hline
\end{tabular}




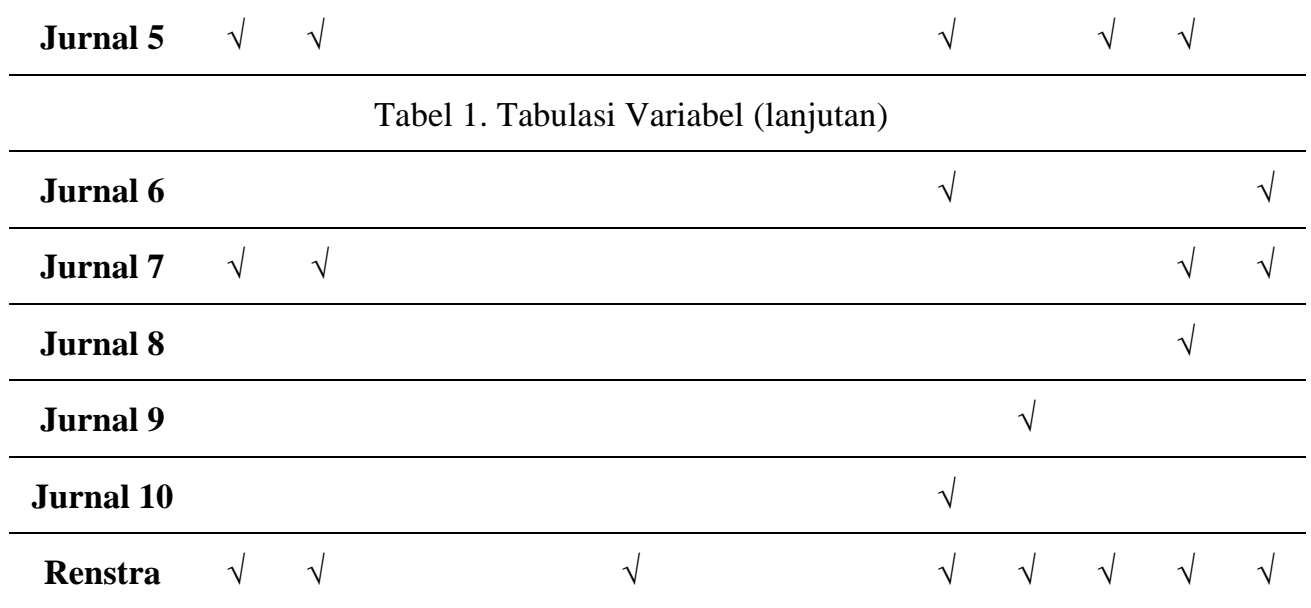

\section{Diagram Alir Penelitian}

Studi ini ingin melakukan analisis faktor demografi dominan yang mempengaruhi proyek konstruksi jalan di pedesaan yang dapat dilihat seperti pada diagram alir pada Gambar 1 .

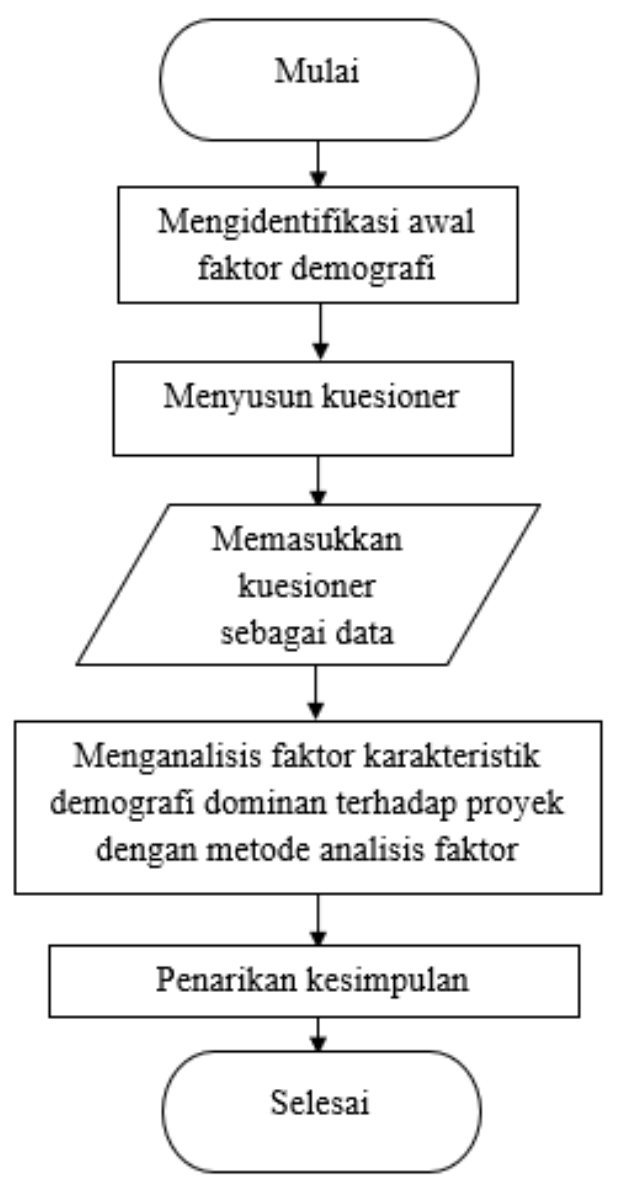

Gambar 1. Diagram Alir Penelitian

\section{Penyusunan Kuesioner}

Dalam penelitian ini instrumen penelitian yang digunakan adalah kuesioner. Penggunaan kuesioner lebih tepat dilakukan di pedesaan dalam melakukan penelitian dibandingkan dengan wawancara dan sejenisnya.

1. Dapat disebarkan untuk responden yang berjumlah besar dengan waktu yang relatif singkat. 
2. Karena diformat dalam bentuk surat, maka biaya lebih murah.

3. Penggunaan waktu yang relatif fleksibel sesuai dengan waktu yang telah diberikan peneliti.

4. Dapat menjaring informasi dalam skala luas dengan waktu yang cepat.

Kuesioner dibuat dengan menggunakan skala Likert. Pada kuesioner ini skala likert dengan nilai 1 (satu) merupakan nilai minimal (tidak setuju) sampai dengan nilai 5 (lima) merupakan nilai maksimum (sangat setuju).

\section{Pengumpulan Data}

Kuesioner ini disebarkan/didistribusikan kepada responden yang terlibat dengan proyek konstruksi infrastruktur desa, yaitu kontraktor dari Kemendes PDTu untuk mengumpulkan data-data proyek dan hasil jawaban kuesioner yang diperlukan untuk mengola data. Populasi dalam penelitian ini adalah para kontraktor yang bekerja dalam proyek konstruksi serta berada di kawasan pedesaan Indonesia. Sampel pada penelitian ini diambil 37 responden.

\section{Pengujian Instrumen}

\section{Uji Validitas}

Tujuan uji validitas adalah untuk mengetahui valid atau tidaknya suatu data kuesioner yang diperoleh dari survei. Data dikatakan valid jika ada korelasi dengan skor total. Syarat pengujian adalah nilai pearson correlation $>r_{\text {tabel }}$

\section{Uji Reliabilitas}

Reliabilitas adalah pengujian yang bertujuan untuk mengetahui sejauh mana pengukuran dari suatu tes tetap konsisten setelah dilakukan berulang-ulang terhadap subjek dan dalam kondisi yang sama. Penelitian dianggap dapat diandalkan bila memberikan hasil yang konsisten untuk pengukuran yang sama.

\section{Pengujian Data}

1. Uji Kaiser-Mayer-Olkin measure of sampling adequacy

Kaiser-Mayer-Olkin measure of sampling adequacy (KMO) digunakan untuk menguji kecukupan sampel dalam penelitian analisis faktor. Jika KMO lebih besar dari 0.5, maka diindikasikan jumlah sampel cukup memenuhi untuk digunakan dalam analisis faktor.

\section{Uji Bartlett's Test Sphericity}

Bartlett's Test Sphericity, digunakan untuk menunjukkan korelasi antara variabel secara keseluruhan. Jika signifikansi kurang dari 0.05 menunjukkan adanya korelasi antara variabel secara keseluruhan

\section{Uji Measure of Sampling Adequancy}

Measures of Sampling Adequacy (MSA), jika nilai MSA setiap variabel lebih besar dari 0.5, maka diindikasikan jumlah sampel cukup untuk digunakan di dalam analisis faktor. MSA digunakan untuk menguji kecukupan variabel yang digunakan untuk analisis faktor.

4. Uji Komunalitas

Komunalitas (communalities), tabel communalities menjelaskan bahwa pada dasarnya adalah jumlah varian (bisa dalam persentase) suatu variabel yang mula-mula bisa dijelaskan oleh faktor yang ada. Ketentuannya adalah makin besar communalities sebuah variabel, berarti makin erat hubungannya dengan faktor yang terbentuk. Nilai extraction uji komunalitas $>0.5$. Jika variabel dengan nilai extraction $<0.5$, maka variabel tersebut harus dikeluarkan dan melakukan pengujian ulang.

\section{ANALISIS DAN PEMBAHASAN}

\section{Uji Validitas}

Tabel 2. Output Bivariate Variabel

\begin{tabular}{llrrr}
\hline & & Total Score & r tabel & Hasil \\
& & & & \\
\hline \multirow{2}{*}{ tenaga kerja } & Pearson Correlation & 0.846 & 0.325 & Valid \\
& Sig. (2-tailed) & .000 & & \\
& $N$ & 37 & & \\
\multirow{2}{*}{ tingkat penghasilan } & Pearson Correlation & 0.351 & 0.325 & Valid \\
& Sig. (2-tailed) & .008 & & \\
& & & &
\end{tabular}




\begin{tabular}{llrrr}
\hline & $N$ & 37 & & \\
\hline \multirow{3}{*}{ Urbanisasi } & Pearson Correlation & 0.889 & 0.325 & Valid \\
& Sig. (2-tailed) & .000 & & \\
& $N$ & 37 & & \\
\hline \multirow{3}{*}{ Usia } & Pearson Correlation & 0.688 & 0.325 & Valid \\
& Sig. (2-tailed) & .000 & & \\
& $N$ & 37 & & \\
\hline \multirow{3}{*}{ Pendidikan } & Pearson Correlation & 0.927 & 0.325 & Valid \\
& Sig. (2-tailed) & .000 & & \\
& $N$ & 37 & & \\
jenis kelamin & Pearson Correlation & 0.912 & 0.325 & Valid \\
& Sig. (2-tailed) & .000 & & \\
& $N$ & 37 & & \\
\hline \multirow{3}{*}{ Lokasi } & Pearson Correlation & 0.564 & 0.325 & Valid \\
& Sig. (2-tailed) & .000 & & \\
& $N$ & 37 & & \\
\hline \multirow{3}{*}{ pengalaman } & Pearson Correlation & 0.578 & 0.325 & Valid \\
& Sig. (2-tailed) & .000 & & \\
\hline
\end{tabular}

\section{Uji Reliabilitas}

Tabel 3. Case Processing Summary

\begin{tabular}{cccc}
\hline \multirow{4}{*}{ Case Processing Summary } \\
\hline \multirow{3}{*}{ Cases } & & N & $\%$ \\
\cline { 2 - 4 } & Valid & 37 & 100.0 \\
\cline { 2 - 4 } & Excluded $^{a}$ & 0 & 0.0 \\
\hline & Total $^{*}$ & 37 & 100.0 \\
\hline
\end{tabular}

a. Listwise deletion based on all variables in the procedure.

Tabel 4. Output Cronbach's Alpha

\begin{tabular}{|c|c|}
\hline \multicolumn{2}{|c|}{ Reliability Statistics } \\
\hline $\begin{array}{c}\text { Cronbach's } \\
\text { Alpha }\end{array}$ & $\begin{array}{l}\text { Nof } \\
\text { Items }\end{array}$ \\
\hline 0.884 & 8 \\
\hline
\end{tabular}

Uji KMO (Kaiser-Mayer-Olkin Measure of Sampling Adequacy) dan Uji Bartlett's Test Sphericity

Tabel 5. Output Uji KMO dan Bartlet

\begin{tabular}{ll}
\hline \multicolumn{2}{c}{ KMO and Bartlett's Test } \\
\hline Kaiser-Meyer-Olkin \\
Measure of Sampling 0.772 \\
Adequacy.
\end{tabular}


Uji MSA (Measures of Sampling Adequacy)

Tabel 6. Output Uji MSA

\begin{tabular}{|c|c|c|c|c|c|c|c|c|}
\hline \multicolumn{9}{|c|}{ Anti-image Matrices } \\
\hline & & $\begin{array}{c}\text { tenaga } \\
\text { kerja }\end{array}$ & urbanisasi & usia & pendidikan & $\begin{array}{c}\text { jenis } \\
\text { kelamin }\end{array}$ & lokasi & pengalaman \\
\hline \multirow{7}{*}{$\begin{array}{l}\text { Anti-image } \\
\text { Covariance }\end{array}$} & $\begin{array}{l}\text { tenaga } \\
\text { kerja }\end{array}$ & 0.285 & -0.079 & $\begin{array}{c}- \\
0.087 \\
\end{array}$ & -0.053 & 0.069 & -0.097 & -0.034 \\
\hline & urbanisasi & -0.079 & 0.144 & 0.088 & -0.060 & -0.081 & 0.036 & 0.030 \\
\hline & usia & -0.087 & 0.088 & 0.316 & -0.067 & -0.119 & 0.081 & 0.150 \\
\hline & pendidikan & -0.053 & -0.060 & $\begin{array}{c}- \\
0.067 \\
\end{array}$ & 0.130 & -0.028 & 0.021 & -0.085 \\
\hline & $\begin{array}{c}\text { jenis } \\
\text { kelamin }\end{array}$ & 0.069 & -0.081 & $\begin{array}{c}- \\
0.119\end{array}$ & -0.028 & 0.159 & -0.091 & -0.019 \\
\hline & lokasi & -0.097 & 0.036 & 0.081 & 0.021 & -0.091 & 0.593 & -0.196 \\
\hline & pengalaman & -0.034 & 0.030 & 0.150 & -0.085 & -0.019 & -0.196 & 0.509 \\
\hline \multirow{7}{*}{$\begin{array}{l}\text { Anti-image } \\
\text { Correlation }\end{array}$} & $\begin{array}{l}\text { tenaga } \\
\text { kerja }\end{array}$ & $.830^{\mathrm{a}}$ & -0.390 & $\begin{array}{c}- \\
0.291 \\
\end{array}$ & -0.273 & 0.322 & -0.237 & -0.090 \\
\hline & urbanisasi & -0.390 & $.764^{\mathrm{a}}$ & 0.414 & -0.437 & -0.538 & 0.125 & 0.110 \\
\hline & usia & -0.291 & 0.414 & $.647^{\mathrm{a}}$ & -0.331 & -0.528 & 0.187 & 0.374 \\
\hline & pendidikan & -0.273 & -0.437 & $\begin{array}{c}- \\
0.331 \\
\end{array}$ & $.848^{\mathrm{a}}$ & -0.197 & 0.076 & -0.329 \\
\hline & $\begin{array}{c}\text { jenis } \\
\text { kelamin }\end{array}$ & 0.322 & -0.538 & $\begin{array}{c}- \\
0.528\end{array}$ & -0.197 & $.768^{\mathrm{a}}$ & -0.296 & -0.066 \\
\hline & lokasi & -0.237 & 0.125 & 0.187 & 0.076 & -0.296 & $.747^{\mathrm{a}}$ & -0.357 \\
\hline & pengalaman & -0.090 & 0.110 & 0.374 & -0.329 & -0.066 & -0.357 & $.727^{\mathrm{a}}$ \\
\hline
\end{tabular}

a. Measures of Sampling Adequacy(MSA)

\section{Uji Komunalitas (Communalities)}

Tabel 7. Output Communalities

\begin{tabular}{ccc}
\hline \multicolumn{3}{c}{ Communalities } \\
\hline Variabel & Initial & Extraction \\
\hline tenaga kerja & 1.000 & 0.746 \\
\hline Urbanisasi & 1.000 & 0.840 \\
\hline Usia & 1.000 & 0.799 \\
\hline Pendidikan & 1.000 & 0.908 \\
\hline jenis kelamin & 1.000 & 0.851 \\
\hline Lokasi & 1.000 & 0.708 \\
\hline Pengalaman & 1.000 & 0.786 \\
\hline
\end{tabular}




\section{KESIMPULAN DAN SARAN}

\section{Kesimpulan}

Hasil analisis didapatkan 7 (tujuh) faktor demografi dominan yang mempengaruhi proyek konstruksi di pedesaan Indonesia, sebagai berikut:

1. Pendidikan

2. Jenis Kelamin

3. Usia

4. Urbanisasi

5. Tenaga Kerja

6. Pengalaman

7. Lokasi

Dari hasil analisis menunjukkan bahwa ada 37 data responden yang valid dan variabel tingkat penghasilan tidak lolos uji MSA. Sehingga variabel tersebut tidak dipakai.

\section{Saran}

Berdasarkan hasil analisis data dan kesimpulan, maka saran yang dapat diberikan adalah sebagai berikut:

1. Pengukuran pengaruh proyek konstruksi jalan pedesaan pada penelitian ini hanya berdasarkan demografi saja. Untuk penelitian selanjutnya, dapat menggunakan indikator lain untuk mengukur pengaruh proyek konstruksi jalan di pedesaan seperti pengaruh berdasarkan aspek legal dan lain-lain.

2. Penelitian dapat dilanjutkan dengan membagikan kuesioner, wawancara, atau kunjungan langsung ke responden lain yang merupakan pemangku kepentingan dalam proyek-proyek pedesaan di KEMENDES.

\section{DAFTAR PUSTAKA}

Bogue, Donald J. Principle of Demography. New York: John Wiley and Son, 1969.

Day, J. dan Ellis, P. Urbanization for Everyone: Benefits of Urbanization in Indonesia's Rural Regions. Journal of Urban Planning and Development. Vol. 140. No. 3 September 2014: 1943-5444.

Direktorat Jenderal Pengembangan Daerah Tertentu. Reviu Rencana Strategis Direktorat Jenderal Pengembangan Daerah Tertentu Renstra Ditjen PDTu 2015-2019. Jakarta: Kemendesa, 2015.

Ramli, M.Z., Malek, M.A.,Lin, C.L. Study of Factors Influencing Construction Delays at Rural Area in Malaysia. Journal of Physics: Conference Series. Juli 2018: 1742-6596.

Tran, D.Q., Hallowell, M.R., dan Molenaar, K.R. Construction Management Challenges and Best Practices for Rural Transit Projects. Journal of Management in Engineering. Vol. 31. No. 5 September 2015: 1943-5479. 
Faktor Demografi Dominan yang Mempengaruhi Proyek

Samuel Semaya, et al. Konstruksi Jalan di Pedesaan Indonesia 